\title{
Parasitismo de ovos de Tibraca limbativentris Stål (Hemiptera: Pentatomidae) em lavoura de arroz irrigado, Eldorado do Sul, RS
}

\author{
Egg parasitism of Tibraca limbativentris Stål (Hemiptera: Pentatomidae) \\ in irrigated rice crops, Eldorado do Sul, RS
}

\author{
Thiago Della Nina Idalgo ${ }^{*}$, Josué Sant'Ana ${ }^{2}$, Luiza Rodrigues Redaelli², Patricia Daniela da Silva Pires ${ }^{2}$
}

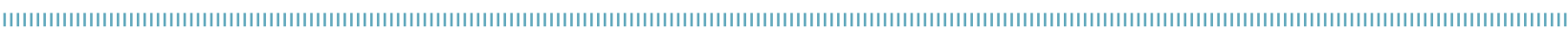

RESUMO: O percevejo-do-colmo, Tibraca limbativentris Stål (Hemiptera: Pentatomidae), é uma importante praga da cultura do arroz no Brasil. O presente trabalho objetivou registrar a ocorrência de parasitoides de ovos de T. limbativentris em lavoura de arroz irrigado, situada no município de Eldorado do Sul, Rio Grande do Sul. A área $\left(603 \mathrm{~m}^{2}\right)$ foi vistoriada semanalmente, de 21/01/2010 a 03/03/2010, coletando-se posturas do percevejo-do-colmo. Constatou-se somente a ocorrência de Telenomus podisi (Ashmead) (Hymenoptera: Platygastridae) como parasitoide de ovos, sendo o índice de parasitismo de $75 \%$. Este é o primeiro registro de T. podisi em ovos do percevejodo-colmo em lavouras de arroz no Rio Grande do Sul.

PALAVRAS-CHAVE: Oryza sativa; percevejo-do-colmo; controle biológico; parasitoide; Telenomus podisi.

\begin{abstract}
The rice stem stink bug, Tibraca limbativentris Stål (Hemiptera: Pentatomidae), is an important pest of rice in Brazil. This study aimed to register egg parasitoids of T. limbativentris in irrigated rice crop in Eldorado do Sul (state of Rio Grande do Sul, Brazil). The area $\left(603 \mathrm{~m}^{2}\right)$ was inspected weekly from $01 / 21 / 2010$ to $03 / 03 / 2010$ and rice stem stink bug eggs were collected. It was observed only the occurrence of Telenomus podisi (Ashmead) (Hymenoptera: Platygastridae) as egg parasitoid and the parasitism rate was $75 \%$. This is the first record of $T$. podisi in rice stem stink bug eggs collected in rice fields in the state of Rio Grande do Sul.
\end{abstract}

KEYWORDS: Oryza sativa; rice stem stink bug; biological control; parasitoid; Telenomus podisi. 
O cultivo do arroz irrigado (Oryza sativa L.) está presente em todas as regióes brasileiras, com destaque para os estados do sul do país, os quais são responsáveis por 75,2\% da produção nacional, sendo que 66,5\% desta é oriunda do Rio Grande do Sul (IBGE, 2011).

Os pentatomídeos são considerados um dos principais problemas na cultura do arroz e podem ocasionar perdas de até $80 \%$ em altas infestaçóes (Ferreira, 2006). Destaca-se dentre estes o percevejo-do-colmo, Tibraca limbativentris Stål (Hemiptera: Pentatomidae), que ataca em todos os estádios da cultura, podendo já estar presente na lavoura a partir do perfilhamento (MarTins et al., 2009; Sosbai, 2012). Em altas infestaçôes, T. limbativentris provoca perdas consideráveis na produçấo, principalmente se o ataque ocorrer nas fases de pré-floração e formação dos gráos (Sosbai, 2012). O ataque do inseto na fase vegetativa resulta na morte das folhas centrais, sinal conhecido como "coração-morto" e, na fase reprodutiva, prejudica a formação dos grãos, ocasionado o sintoma denominado de "panícula-branca" (MarTins et al., 2009). O parasitismo em ovos de T. limbativentris já foi constatado em arrozais do Maranhão (Maciel et al., 2007) e de Santa Catarina (RIffel et al., 2010). No entanto, não há registros em lavouras no Rio Grande do Sul. O presente estudo objetivou registrar as espécies de parasitoides presentes em ovos de T. limbativentris em arroz irrigado no Rio Grande do Sul.

O trabalho foi conduzido no município de Eldorado do Sul, Rio Grande do Sul (3001’ 22,73” S, 51 $1^{\circ} 20^{\prime} 49,25^{\prime \prime}$ O), em lavoura de arroz da variedade Epagri 109, semeada no início de outubro de 2009 por aviáo no sistema de plantio pré-germinado. O experimento foi realizado entre 21/01/2010 e 03/03/2010, compreendendo os períodos relativos ao desenvolvimento da panícula (R0) até a colheita (R7). As amostragens foram realizadas em uma área de $603 \mathrm{~m}^{2}$, isenta de inseticidas, sendo esta delimitada por lavoura de arroz ao norte e por canal de irrigação ao sul, leste e oeste. Conforme os registros meteorológicos da Estação Experimental Agronômica da Universidade Federal do Rio Grande do Sul (UFRGS), as médias de temperatura, umidade relativa do ar e precipitação pluviométrica durante o período das amostragens foram de $24,7^{\circ} \mathrm{C}, 83,4 \%$ e $3,6 \mathrm{~mm}$, respectivamente. As avaliaçóes foram realizadas sempre no turno da manhá, entre 9 e 11 horas, ao longo de 7 semanas. Cada unidade amostral consistiu de uma área de $1 \mathrm{~m}^{2}$, delimitada por uma armação de madeira, lançada aleatoriamente em 10 pontos na lavoura. As plantas no interior do quadrado foram vistoriadas por 10 minutos e todas as posturas de T. limbativentris foram coletadas. As posturas foram acondicionadas em caixa de isopor, levadas para o laboratório e individualizadas em placas de Petri plásticas (8,5 $\mathrm{cm} \varnothing)$ contendo papel filtro umedecido e envoltas com parafilme. As placas foram identificadas segundo a data da coleta e a unidade amostral da qual eram provenientes. Estas eram vistoriadas diariamente e mantidas em condiçôes controladas
( $25 \pm 2^{\circ} \mathrm{C}$ e fotofase de 12 horas). Os parasitoides emergidos foram conservados em álcool 70\% em tubos Eppendorf e, posteriormente, identificados pelo Dr. Valmir Antonio Costa, do Instituto Biológico de Sáo Paulo. Os ovos nos quais náo se observou eclosão ou emergência foram posteriormente abertos e, quando possível, contabilizada a presença de ninfas ou parasitoides. Os números médios de ovos coletados e parasitados foram comparados entre as ocasióes de amostragem pelo teste de Kruskal-Wallis, a 5\% de significância. A correlação entre a média do número de ovos parasitados e os fatores climáticos foi avaliada pelo teste de correlação linear.

Foram coletadas no total 114 posturas com 3.409 ovos, dos quais eclodiram 475 ninfas (13,9\%) e emergiram 897 parasitoides (26,3\%). Registrou-se desenvolvimento ninfal sem eclosão em 141 ovos (4,1\%). Em 48,7\% dos ovos parasitados (1.661), não foi constatada a emergência. Do total amostrado, 235 ovos eram inférteis (6,9\%).

Observou-se a ocorrência apenas do parasitoide Telenomus podisi (Ashmead) (Hymenoptera: Platygastridae). Essa espécie é reconhecidamente generalista e tem uma grande gama de hospedeiros como os pentatomídeos: Euschistus heros (Fabricius), Piezodorus guildinii (Westwood), Nezara viridula (Linnaeus) (Medeiros et al., 1997; Pacheco; Corrêa-Ferreira, 2000; Maruyama et al., 2002; Godor et al., 2005) e T. limbativentris (Maciel et al., 2007; Riffel et al., 2010). Telenomus. podisi é capaz de estabelecer-se como o principal agente de controle biológico de percevejos, sendo por vezes o parasitoide mais abundante encontrado em posturas de heterópteros (Medeiros et al., 1997; Godoy et al., 2005; Maciel et al., 2007; Riffel et al., 2010). De acordo com Riffel et al. (2010), T. podisi foi a única espécie encontrada em posturas de T. limbativentris nas lavouras de arroz dos municípios de Meleiro e Tubarão, Santa Catarina.

$\mathrm{O}$ índice de ovos parasitados registrado no presente estudo foi de $75 \%$, com um sucesso de parasitismo, ou seja, percentual de emergência, de 35,1\%. O número médio total de ovos por metro quadrado náo variou entre as ocasiōes de amostragem $(\mathrm{H}=9,5712 ; \mathrm{gl}=6 ; \mathrm{p}=0,1439)$, assim como o de ovos parasitados $(\mathrm{H}=4,2714 ; \mathrm{gl}=6$; $\mathrm{p}=0,64)$ (Fig. 1). Não foi observada influência dos fatores pluviosidade $\left(\mathrm{p}=0,4679 ; \mathrm{R}^{2}=0,1095\right)$, temperatura $(\mathrm{p}=0,1486$; $\left.\mathrm{R}^{2}=0,368\right)$ e umidade relativa do ar $\left(\mathrm{p}=0,7324 ; \mathrm{R}^{2}=0,0255\right)$ sobre o número médio de ovos parasitados ao longo do período de amostragem.

Em lavoura de soja no Distrito Federal, foram observados índices de parasitismo por T. podisi, Trissolcus basalis (Wollaston) e Trissolcus urichi (Crawford) (Hymenoptera: Scelionidae) superiores a $70 \%$ em ovos de E. heros e P. guildinii (Medeiros et al., 1997; 1998). Nessa mesma cultura, porém em Londrina, Paraná, Pacheco; CorrêA-Ferreira (2000) constataram mais de $80 \%$ dos ovos de $P$. guildinii e $E$. heros parasitados por T. podisi. Valor inferior de parasitismo pela mesma espécie (50\%) foi registrado por Godoy et al. (2005) 


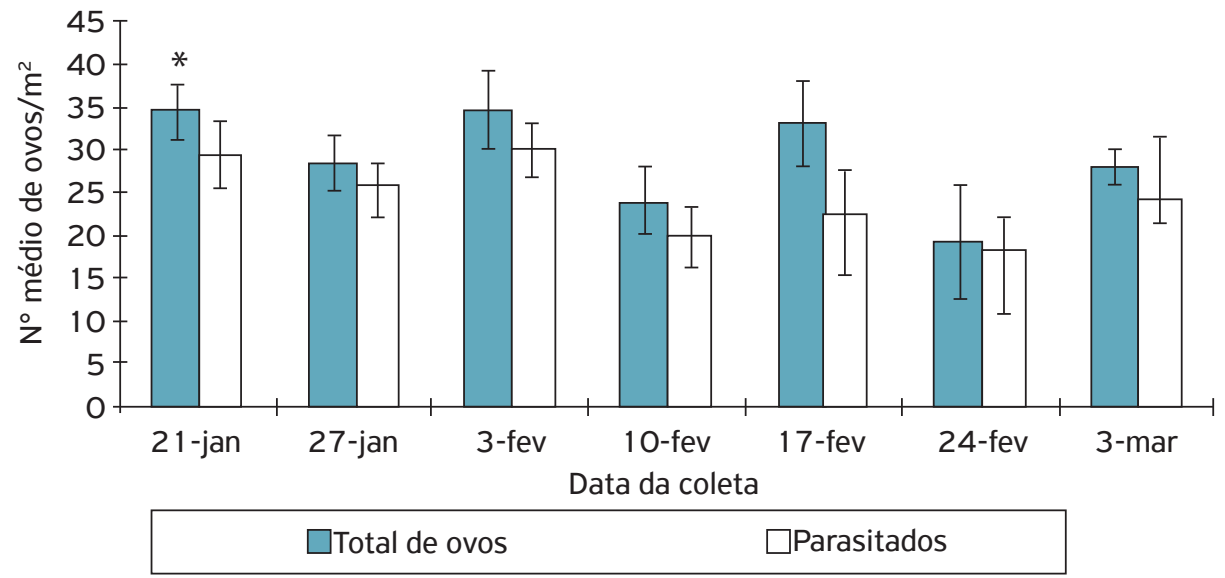

${ }^{*}$ Colunas entre datas não diferem entre si pelo teste de Kruskal-Wallis ( $\left.a=0,05\right)$.

Figura 1. Número médio ( \pm erro padrão) total de ovos de Tibraca limbativentris coletados e parasitados por ocasião de amostragem no período de 21/01/2010 a 03/03/2010, em lavoura de arroz no município de Eldorado do Sul, Rio Grande do Sul.

em ovos de E. heros em soja, no município de São Gabriel do Oeste, Mato Grosso do Sul.

O parasitismo em ovos de T. limbativentris foi primeiramente constatado por MACIEL et al. (2007), os quais observaram $23,4 \%$ de parasitoides emergidos em ovos coletados no Maranhăo, em lavouras de arroz. Segundo os autores, as espécies encontradas foram Oencyrtus submetallicus (Howard) (Hymenoptera: Encyrtidae), T. podisi e T. urichi, sendo as duas últimas as mais frequentes e abundantes. Estas também foram registradas por Riffel et al. (2010) em Santa Catarina, na mesma cultura e hospedeiro, sendo constatado um percentual total de parasitismo superior a $70 \%$ por T. podisi. Os resultados obtidos por esses autores corroboram os do presente estudo.

Sendo assim, ressalta-se a importância da utilização de agrotóxicos mais seletivos ao se planejar o controle químico voltado para T. limbativentris. Ademais, a liberação de T. podisi poderá ser uma importante alternativa para o controle do percevejo-do-colmo em lavouras de arroz no Rio Grande do Sul.

\section{AGRADECIMENTOS}

Ao Conselho Nacional de Desenvolvimento Científico e Tecnológico $(\mathrm{CNPq})$ - Luiza Rodrigues Redaelli processo no 305956/2010-8 — e à Coordenação de Aperfeiçoamento de Pessoal de Nível Superior (CAPES) pela concessão de bolsa de pesquisa aos autores. Ao Dr. Valmir Antonio Costa, do Instituto Biológico de São Paulo, pela identificação dos parasitoides.

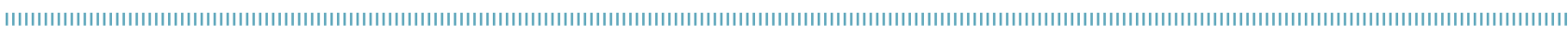

\section{REFERÊNCIAS}

FERREIRA, E. Fauna prejudicial. In: SANTOS, A.B.; STONE, L.F.; VIEIRA, N.R.A. (Eds.). A cultura do arroz no Brasil. 2. ed. Santo Antônio de Goiás: Embrapa Arroz e Feijão, 2006. p.485-560.

GODOY, K.B.; GALLI, J.C.; ÁVILA, C.J. Parasitismo em ovos de percevejos da soja Euschistus heros (Fabricius) e Piezodorus guildinii (Westwood) (Hemiptera: Pentatomidae) em São Gabriel do Oeste, MS. Ciência Rural, v.35, p.455-458, 2005.

INSTITUTO BRASILEIRO DE GEOGRAFIA E ESTATÍSTICA (IBGE). Levantamento sistemático da produção agrícola: pesquisa mensal de previsão e acompanhamento das safras agrícolas no ano civil. Rio de Janeiro, v.24, n.8, p.1-82,
2011. Disponível em: <http://www.ibge.gov.br/home/ estatistica/indicadores/agropecuaria/Ispa/Ispa_201108. pdf> Acesso em: 12 nov. 2011.

MACIEL, A.A.S.; LEMOS, R.N.S.; SOUZA, J.R.; COSTA, V.A.; BARRIGOSSI, J.A.F.; CHAGAS, E.F. Parasitismo de ovos de Tibraca limbativentris Stal (Hemiptera: Pentatomidae) na cultura do arroz no Maranhão. Neotropical Entomology, v.36, n.4, p.616-618, 2007.

MARTINS, J.F.S.; BARRIGOSSI, J.A.F.; OLIVEIRA, J.V.; CUNHA, U.S. Situação do manejo integrado de insetos-praga na cultura do arroz no Brasil. Pelotas: Embrapa Clima Temperado, 2009. (Documentos, 290). 
MARUYAMA, W.I.; PINTO, A.S.; GRAVENA, S. Parasitóides de ovos de percevejos (Hemiptera: Heteroptera) em plantas daninhas. Revista Ceres, v.49, p.453-459, 2002.

MEDEIROS, M.A.; LOIÁCONO, M.S.; BORGES, M.; SCHIMIDT, F.V.G. Incidência natural de parasitoides em ovos de percevejos (Hemiptera: Pentatomidae) encontrados na soja no Distrito Federal. Pesquisa Agropecuária Brasileira, v.33, p.1431-1435, 1998.

MEDEIROS, M.A.; SCHIMIDT, F.V.G.; LOIÁCONO, M.S.; CARVALHO V.F.; BORGES, M. Parasitismo e predação em ovos de Euschistus heros (Fab.) (Heteroptera: Pentatomidae) no Distrito Federal, Brasil. Anais da Sociedade Entomológica do Brasil, v.26, n.2, p.397-401, 1997.
PACHECO, D.J.P.; CORRÊA-FERREIRA, B.S. Parasitismo de Telenomus podisi Ashmead (Hymenoptera: Scelionidae) em populações de percevejos pragas da soja. Anais da Sociedade Entomológica do Brasil, v.29, n.2, p.295-302, 2000.

RIFFEL, C.T.; PRANDO, H.F.; BOFF, M.I.C. Primeiro relato de ocorrência de Telenomus podisi (Ashmead) e Trissolcus urichi (Crawford) (Hymenoptera: Scelionidae) como parasitoides de ovos do percevejo-do-colmo-do-arroz, Tibraca limbativentris (Stål) (Hemiptera: Pentatomidae), em Santa Catarina. Neotropical Entomology, v.39, n.3, p.447-448, 2010.

SOCIEDADE SUL-BRASILEIRA DE ARROZ IRRIGADO (SOSBAI). Arroz irrigado: recomendações técnicas da pesquisa para o Sul do Brasil. Itajaí: SOSBAI, 2012. 